\title{
A review of process safety catastrophes on the Texas Gulf Coast
}

\author{
R. G. Carranza \\ Chemical Process Engineering Consultant, Montgomery, Texas, USA
}

\begin{abstract}
Catastrophes related to processing facilities on the Texas Gulf Coast are reviewed. Most information is taken from the Chemical Safety and Hazard Investigation Board (CSB). The cases are condensed and presented such that only the essential material required is included. The Board's recommendations are highlighted. Statistics are presented from the Bureau of Labor Statistics and the Bureau of Economic Analysis indicating the rates of injuries and deaths in the industry. Furthermore, personal observations are made which include commentary based on the author's 25 years of industry experience.

Keywords: chemical, process, safety, CSB, OSHA, ASME, refinery, petroleum.
\end{abstract}

\section{Introduction}

Four different process safety catastrophe case studies are presented for review, all located along the Texas Gulf Coast: Marcus Oil, British Petroleum, Formosa Plastics, and Goodyear Tire and Rubber. Statistics from the federal government are also presented and suggest that, overall, injuries and fatalities are decreasing - that is, since 2003. And lastly, personal experience is used to shine some light on why these catastrophes are occurring.

\subsection{Marcus Oil and Chemical, Houston, Texas: polyethylene wax processing facility explosion and fire, December 3, 2004}

The incident at Marcus Oil [1] is interesting because it is really more political than it is technical. After an investigation by CSB, Marcus Oil is found, for the most part, not guilty of breaking any federal law; nor to be in violation of any local regulations. The industrial standards relating to this case are ASME code section VIII, State of Texas and City of Houston regulations, National Board 
Inspection Code NB-23, OSHA Process Safety Management Standard, and the International Fire Code.

Marcus Oil processes high density polyethylene wax. Hexane and other hydrocarbons are extracted, stored in tanks above ground, and sold. The processed wax is pelletized for sale. When the wax (called "rag") is separated from the lighter hydrocarbons, it is placed in tanks. The environment of the tank is made inert with nitrogen blanketing. When the rag is to be further refined and pelletized, steam coils in the tanks melt the wax and the liquid wax is flowed out of the vessel and to a pump using the nitrogen as a motive force. Tank 7 is one tank used for storing the molten rag. The process is described in fig. 1 .

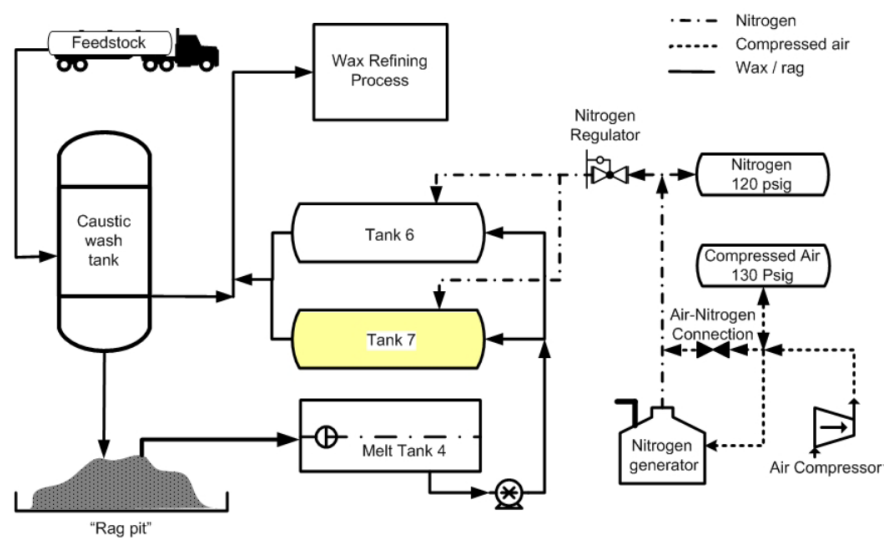

Figure 1: Schematic of Marcus Oil processing facility for polyethylene wax [1].

CSB determines that Marcus Oil alters the vessel design of several tanks on the property, including Tank 7. A 24 inch hole is cut in Tank 7 to install and maintain the steam coils. A metal plate is welded over the hole that does not adhere to ASME section VIII. The poor welding fails when the vessel is pressurized with nitrogen to $67 \mathrm{psig}$, the regulator set pressure.

Furthermore, the company's nitrogen generator is incapable of supplying sufficient nitrogen to the system. A bypass line is connected to the company's plant air system to supplement the nitrogen system during peak times. Thus, the oxygen content in the gas blanket over Tank 7 is $18 \%$ oxygen instead of the desired maximum of $8 \%$.

When the plate is blown from the tank, it hits the ground and creates a spark. The molten hydrocarbon is in an oxygen rich environment and an explosion occurs. The heads on the tank are shattered and the 50,000 pound vessel is hurled 150 feet. Luckily, no deaths occur. Some local residents are slightly injured due to flying debris and concussion. Three fire fighters sustain minor injuries.

CSB discloses the following facts: 
- Since the State of Texas does not require facilities to abide by ASME section VIII nor the National Board Inspection Code NB-23, the facility is not at fault. Normally these codes have guidelines regarding the construction, repair, hydrotesting, and overpressure protection for pressure vessels.

- The City of Houston does require implicitly that Marcus Oil follow ASME code, since the city has a law relating to vessels containing hazardous materials (as specified by the International Fire code) with inert gases. In other words, although polyethylene wax is not defined as "hazardous" by the City of Houston, Marcus Oil must use ASME code since the vessel utilizes inert gas. The problem is that ASME code only covers new vessels and not modified. Such being the case, the refinery is perfectly within the law to use non-certified welders, to neglect hydrotesting, and not use proper overpressure protection on the vessel. Since the vessel plate is destroyed in the explosion, it cannot be verified that Tank 7 is installed using ASME code; but, other tanks in the facility do have plates indicating adherence to ASME code - so it is assumed that Tank 7 is within code.

- OSHA Process Safety Management standard does not apply in this incident. The reason is that polyethylene is not a "flammable liquid"; and although hexane is flammable, the amount being stored at the facility is well below the 10,000 pound regulatory threshold.

\subsection{British Petroleum, Texas City, Texas: refinery fire, positive material verification, July 28, 2005}

This case relates to a procedural error performed during routine maintenance [2]. The plant is operating a Resid Hydrotreater Unit. High temperature hydrogen is used to remove sulfur and nitrogen as hydrogen sulfide and ammonia. Carbon steel is susceptible to high temperature hydrogen attack (HTHA) at temperatures and pressures above $450^{\circ} \mathrm{F}$ and 100 psia. At these conditions, hydrogen reacts with the carbon in the pipe and forms methane. Thus, low alloy steels containing 1.25-3.0 percent chrome must be used.

Low temperature hydrogen is fed into a couple of heat exchangers in series. Because of the wide range of temperatures in the process, two different types of materials must be used for the piping: carbon steel and low alloy steel (see fig. 2).

As is seen in fig. 2, elbow 1 is made of carbon steel; and elbows 2 and 3 are made from low alloy steel. The reason being temperature variation. However, when the exchangers are disassembled for maintenance in January of 2005, the contractor mistakes elbows 1 and 3 for one another. The elbows are reversed during reassembly. Carbon steel and low alloy steel are indistinguishable to the naked eye.

It is concluded that elbow 3 fails in less than 3000 hours of service due to HTHA. The result is that the hydrogen escapes from the corroded pipe and ignites. British Petroleum requires positive material identification (PMI) for new projects, but does not have a requirement for maintenance projects. PMI is easily accomplished with portable hand-held devices like an X-ray fluorescence 
instrument. Furthermore, the contractor is simply sloppy with respect to tagging piping components and reassembly. The entire event is entirely avoidable with proper tagging. CSB passes these recommendations to both British Petroleum and the contractor. One minor injury to plant personnel is reported and no deaths.

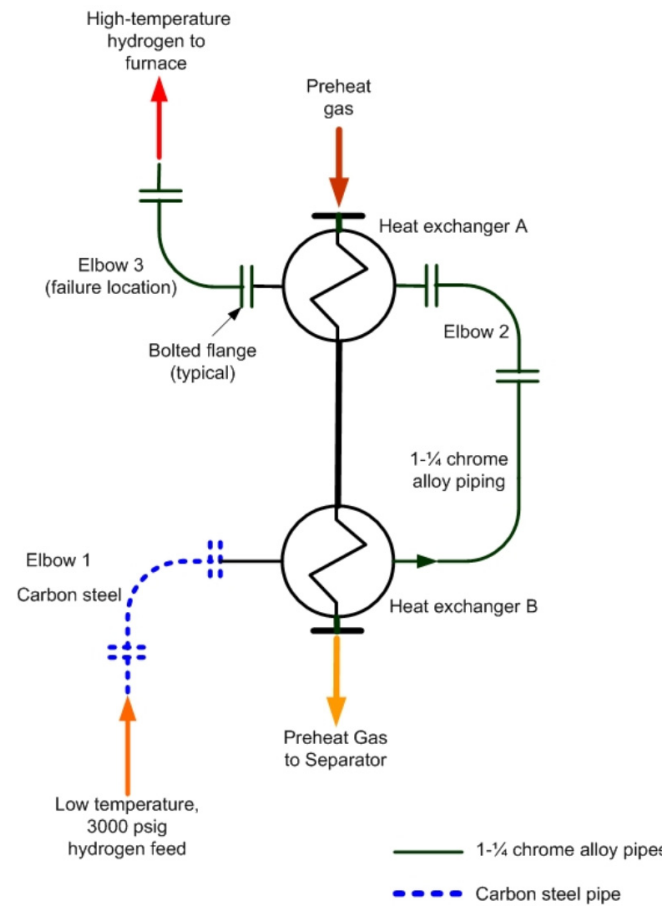

Figure 2: Elbow and heat exchanger arrangement for hydrogen preheat [2].

\subsection{Formosa Plastics, Port Comfort, Texas: olefins unit fire, October 6, 2005}

Formosa Plastics experiences a plant explosion and fire in its Olefins II unit. [3] The reason for the incident is damage to the process piping from a motorized vehicle. A trailer being pulled by a forklift pulls a manual valve off a strainer. Liquid propylene pools on the ground, vaporizes, and explodes. The explosion is categorized as an "unconfined, low speed, deflagration". Fig. 3 is a schematic of the process.

Note that the schematic does not appear to be entirely representative of the situation. A C3 splitter is usually fractionating propylene from propane; thus, the tower product is propylene, but a condenser/heat exchanger seems to be missing between the tower and the pumps.

An analysis of the incident reveals several interesting points: 
- When Formosa conducts a process hazard analysis of the unit, it is determined that barriers protecting process equipment from vehicular collision are necessary; but not for the process area in question because the probability of a collision is highly remote - one in twenty years. Thus, the strainer and associated piping are not protected from vehicular collision.

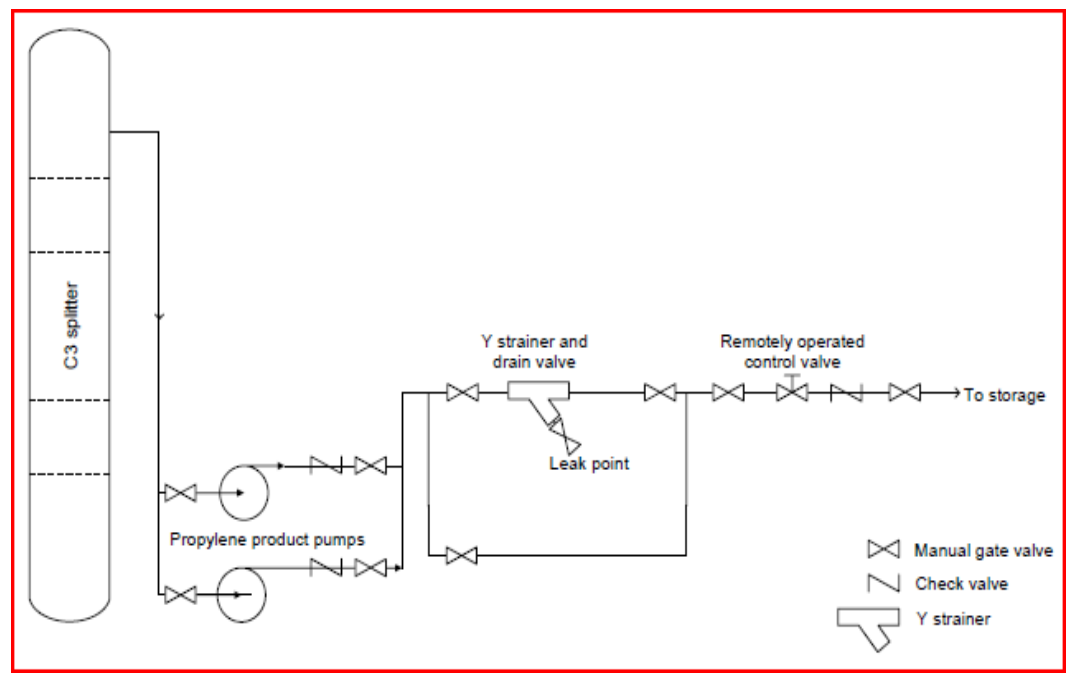

Figure 3: $\quad$ Process Schematic of the Formosa Unit [3].

- Within the area that is consumed with fire, there is a pipe rack that also contains a flare header. Although most of the columns supporting the rack are fireproofed, one row of columns is not. This allows the rack to fall and the piping to the flare is crimped. Propylene, instead of being vented, is allowed to feed the fire. M. W. Kellogg is hired to design the Olefins I unit in $1988-$ at the same time API publishes its fireproofing guidelines, Publication 2218, which states that all flare network piping should be supported by steel columns with fireproofing. In 1996, Formosa hires M. W. Kellogg again, this time to design Olefins II. Kellogg simply uses the old Olefins I design without updating the fireproofing on the steel columns.

- An important point in this study is the fact that Formosa did not isolate the distillation column with automated shutoff valves. The check valve stopped flow from storage; and thus, did not allow the fire to be fueled from this source. However, the distillation column is a source of fuel and there is nothing to prevent the fire from being fueled by this source. CSB recommends that all vessels with large inventories of flammable materials be isolated with automated valves. Formosa only has hand valves to shutoff flow to the fire that originates from the distillation column.

- Formosa does not require employees to wear flame retardant clothing in the unit and is cited by OSHA. Formosa contests the citation. Sixteen employees are injured in the incident, one seriously. 


\subsection{Goodyear Tire and Rubber Company, Houston, Texas: heat exchanger rupture and ammonia release, June 11, 2008}

The explosion at the Goodyear plant killed one worker and injured six others [4]. The reason is operator error. Essentially, a heat exchanger is blocked-in during operation; the resulting overpressure ruptures the vessel, and flings debris and ammonia throughout the production unit.

The scenario revolves around a shift change, overnight:

- Fig. 4 is a schematic of the heat exchanger and the associated piping.

- Ammonia (shell side) is used as a coolant for a reactor feed (tube side).

- On the late afternoon of June $10^{\text {th }}$, an operator closes the isolation valve to the shell side relief valve in order to replace a rupture disk.

- The disk is replaced but the isolation valve is not reopened.

- Early the next morning, a worker closes the block valve upstream of the control valve on the shell side exit. The system is now completely blocked-in.

- The worker then flows steam though the tube side to clean the exchanger; however, the extra energy evaporates excessive amounts of ammonia and the exchanger ruptures.

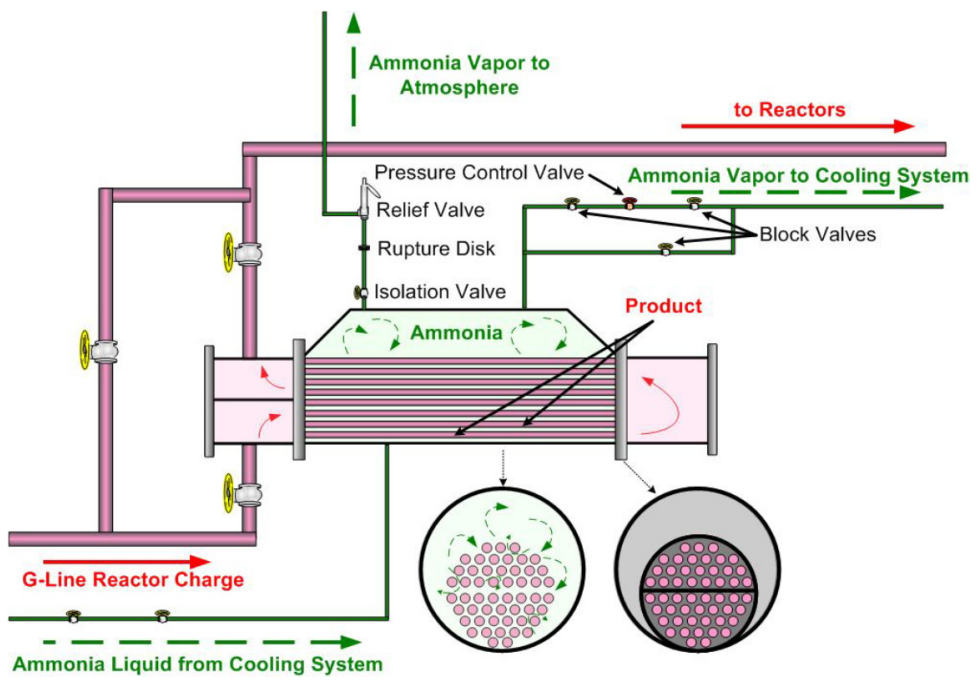

Figure 4: $\quad$ Process schematic of Ammonia Heat Exchanger [4].

Despite the fact that Goodyear's emergency and maintenance procedures are described in one word, "sloppy", the entire incident could have been avoided by following two guidelines provided by ASME Boiler and Vessel Code, Section VIII:

- ". . . when a pressure vessel relief device is temporarily blocked and there is a possibility of vessel pressurization above the design limit, a worker capable of releasing the pressure must continuously monitor the vessel. Goodyear's maintenance procedures did not address over-pressurization by the ammonia 
when the relief line was blocked, nor did it require maintenance and operations staff to post a worker at the vessel to open the isolation valve if the pressure increased above the operating limit." [4]

- “. . . over-pressure protection shall be continuously provided on pressure vessels installed in process systems whenever there is a possibility that the vessel can be over-pressurized by any pressure source, including external mechanical pressurization, external heating, chemical reaction, and liquid to vapor expansion. Workers should continuously monitor an isolated pressure relief system throughout the course of a repair and reopen blocked valves immediately after the work is completed." [4]

In the early afternoon of June $11^{\text {th }}$, the body of Gloria McInnis is found in the general area of the ruptured heat exchanger. She is part of the company's emergency response team, and procedural errors lead to an improper head count - she is mistakenly accounted for as alive and well. Her husband's main concern is whether she dies from the explosion or the ammonia. A search through the internet and the Houston Chronicle's website does not provide an answer.

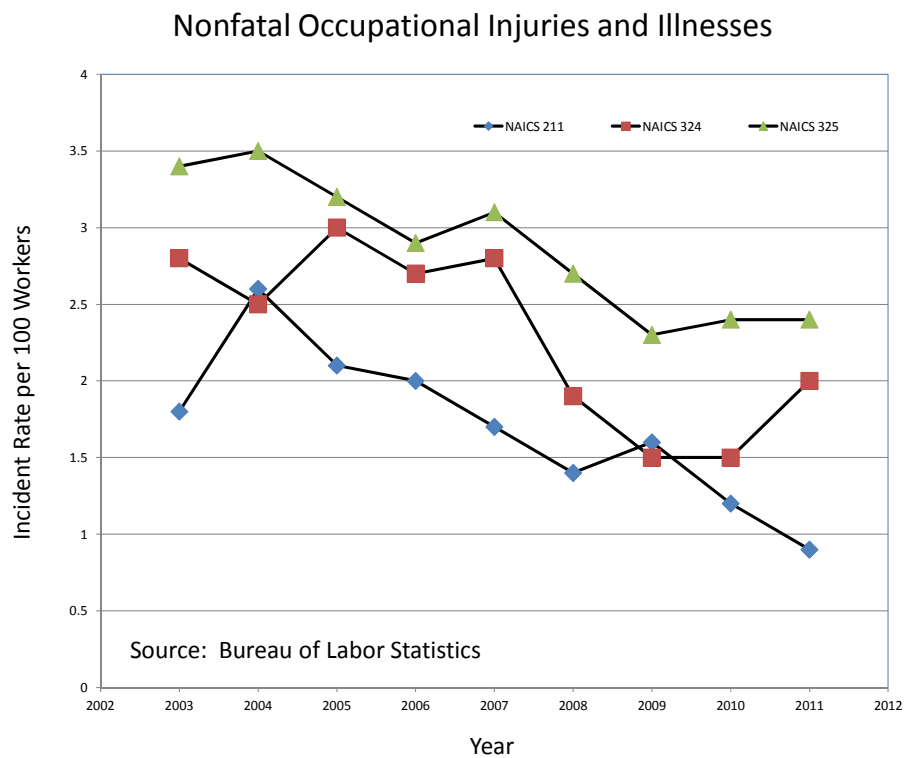

Figure 5: US nonfatal injuries and illnesses rates by industry.

\subsection{Industry injury and fatality statistics}

Industry statistics are provided by the Bureau of Labor Statistics (BLS) and the Bureau of Economic Analysis (BEA). Historically speaking, the government uses the Standard Industry Code (SIC) for classifying industries; but sometime around the year 2000, the government makes an attempt to use a new system: North American Industry Classification System (NAICS). 
This change in systems causes a break in the data. Most of the data in the 1900s is defined by SIC and data from 2000 (approximately) onward is defined by NAICS. Attempts are being made to correlate the two systems but the process is slow. For simplification, this report confines discussion to NAICS, starting at 2003.

NAICS uses 6 numbers to define industries - the first two digits define a broad industry, and the next numbers are used to specifically fix which subsector is being referred. For simplicity, and to avoid "splitting hairs", only three numbers are used in this study.

The industries studied are oil/gas, petroleum, and chemicals:

- NAICS 211 - Oil and Gas Extraction

- NAICS 324 - Petroleum and Coal Products Manufacturing

- NAICS 325 - Chemical Manufacturing

Nonfatal Occupational Injuries and Illnesses

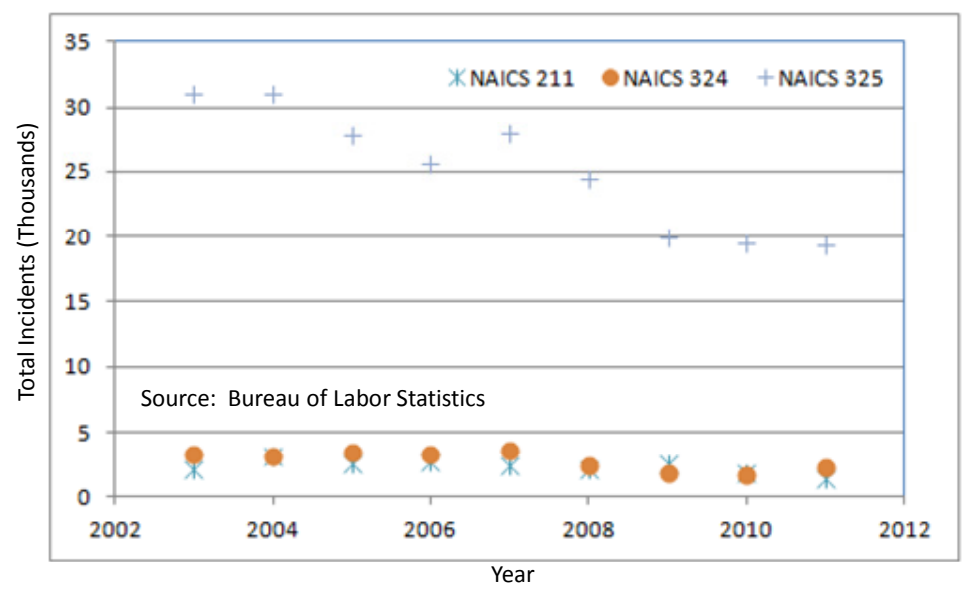

Figure 6: US nonfatal injuries and illnesses totals by industry.

Figs. 5-8 graphically indicate the course of injuries and fatalities in the USA and Texas for the selected industries. The following must be noted for clarity (per BLS):

\section{Incident Rate per 100 Workers = Total Incidents/Total Hours Worked by All Workers * 200,000}

The figure 200,000 refers to the number of hours worked by 100 workers, working 40 hours per week for 50 weeks. Closer analysis of this relationship shows that it is easily reduced to the following form:

Incident Rate per 100 Workers = Total Incidents/Average Annual Employment *100

One more note must be made for clarity. The following data are not presented in this study because BLS does not provide this data, or the data per BLS is incomplete: 
- Texas injury incident rates for NAICS 211 and 324.

- Texas total injuries for NAICS 211 and 324.

- National fatal rates for NAICS 211, 324, and 325.

- Texas fatal incident rates and totals for NAICS 211, 324, 325.

- A data point for the year 2003 and NAICS 324 is missing in fig. 8.

A quick glance at figs. 5-8 makes one thing fairly clear - injuries and fatalities are trending downward since the year 2003. This is important when compared to fig. 9.

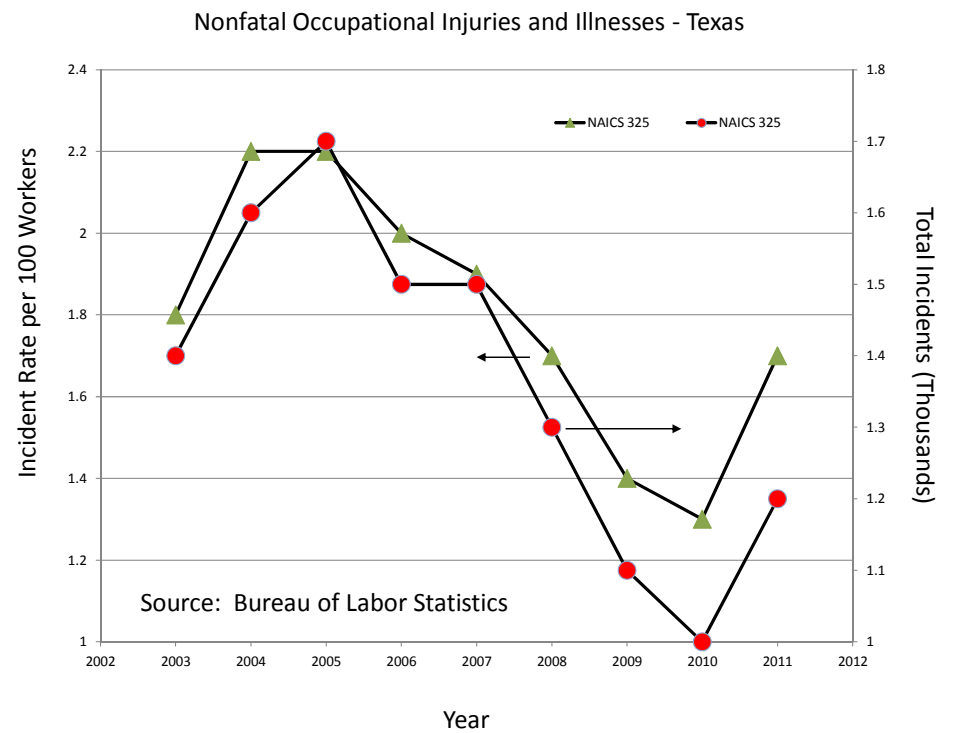

Figure 7: Texas injuries and illnesses incident rate and totals, by industry.

Fig. 9 indicates that the NAICS industries 211, 324, and 325, undergo an economic downturn between the years 2007 and 2010. Yet, injuries and fatalities do not surge upward during this period. It appears that injuries and fatalities actually decline during this period. This is important because there is a belief among people in the industry, the press, and the public at large, that ultimately what matters to corporations are profits; and that people do not matter. Figs. 5-9 do not support this belief - in general, injuries and fatalities are trending downward, particularly during economic hard times.

\section{Conclusion}

Despite the fact that injuries and fatalities are trending downward, the reality still remains that serious and catastrophic explosions and releases are occurring, as is seen in the cases studied in this report. Twenty five years of experience shine some light on why these terrible incidents continue to occur. Although not experimentally conclusive, the following reasons and causes are proposed for discussion: 
- Rushed capital, turnaround, and maintenance schedules.

- General lack of project organization - blurred lines of authority, responsibility, and work flow.

- Many processing facilities have a resident contractor; but, it appears that this is simply "window dressing". Personal experience shows that when flaws in design are brought to the attention of the client by the contractor (flaws that will be costly with respect to vessel alterations, hydrotesting, X-ray examination, PHA reviews, squad checks, etc.), the client just simply explains the flaw away with hypothetical arguments and semantics. Of course, the contractor can only make suggestions - the contractor can be, and often is, easily replaced.

- Personnel skill sets do not match work performance requirements, for instance:

1. Mechanical engineers in a refinery maintenance department charged with leading a pressure relief valve documentation and upgrade project; and yet, do not understand the term "scenario analysis". This is clearly a job for chemical engineers.

2. Instrument technician in charge of orifice plate sizing, and does not understand why the heat capacity ratio and the molecular weight are not required in the calculations if the fluid is a liquid.

3. Instrument technician in charge of selecting liquid level and pressure instruments, when told that the pressure is a product of density, liquid height, and gravitational constant; does not understand why the gravitational constant is in the equation, "if it is a constant".

4. Refinery engineering departments selecting pressure vessels and metallurgy without employing a legitimate mechanical engineering department; rather, the piping designers and process engineering department are used.

5. Piping supervisor (skilled in computer aided design, not engineering) is named project manager and leads process engineers in a pressure relief valve study.

6. In some engineering design firms, civil and electrical engineers are doing chemical process simulation; while chemical and mechanical engineers are selecting process instrumentation, electrical switch gear, transformers, and motor control centers.

7. Electrical engineer with a background in computer circuit boards is hired as a lead instrument engineer on a petroleum refinery revamp project.

As is indicated in figs. 5-9, profits do not appear to be a driving force behind catastrophic incidents in process facilities; however, personal experience tells otherwise. Utilizing designers, with no engineering degree, who have worked their way into the office from the field, is a cheap way to do engineering; but not supportable. Furthermore, using chemical engineers to do electrical systems and using electrical engineers to do process simulation is, perhaps, a way to cut down on manpower; but again, this is unreasonable. And lastly, if resident contractors can be easily replaced by the client, one can rest assured that contractors will not press issues that the client does not want to hear - especially if the issues involve high costs. 
Fatal Occupational Injuries

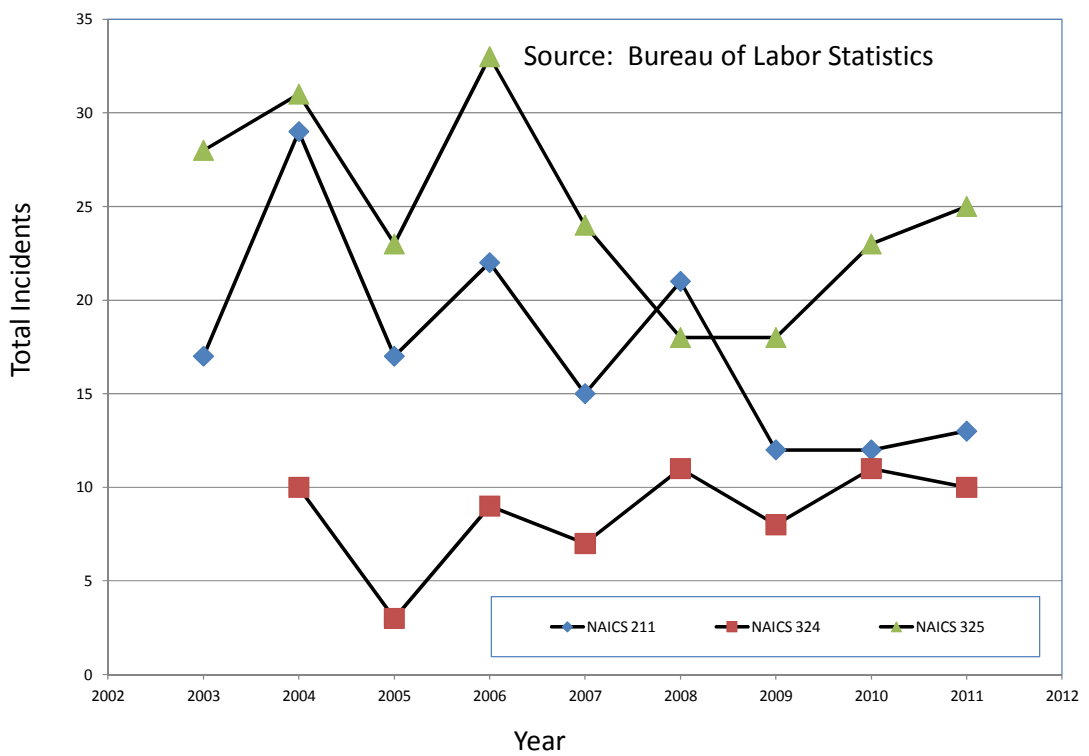

Figure 8: $\quad$ US fatal incidents by industry.

How do things get this way? One suggestion is democracy. A manufacturing environment is very democratic - that is, its life blood is the work produced by unskilled or semi-skilled labor where the educational level usually is not beyond high school. Much effort is made to keep the morale of the worker high; for instance, birthday parties, bowling parties, barbeque parties, pot luck lunches, etc. If there is a plant upset, the intelligentsia normally steps back and says, "let them handle it". The worker very much feels that he is in control because he "makes things go".

Yet, as is described, the manufacturing facility is becoming paralyzed by chaos. This is not surprising. Socrates claims that democracy is the penultimate step before complete chaotic collapse and complete tyranny in a state.

Professor Kenneth Harl, in his online class, "The Peloponnesian War" [5], makes a great observation:

Aristotle, writing at the end of the $4^{\text {th }}$ century B.C., noted that a state's constitution depends heavily on the military obligations of its citizens. . . . Before the advent of the navy, men from the lowest Athenian class (thetes) generally served as auxiliaries or light infantry on the battlefield. They could not perform hoplite service [hoplites are heavily armored soldiers from the propertied class, they buy their own armor, and thus; are wealthy by necessity] and were not taken seriously in the assembly. . . . Once these men became rowers in the fleet of triremes [war ships], they gained a higher position in society and could assert their political rights. . . . Thus, the development of the Athenian navy went hand in hand with the development of democracy. . 
... . naval advancements changed the state into a full participatory democracy with no restrictions on office-holding. To man a fleet of 200 triremes required 34,000 thetes trained as rowers. Inevitably, these men realized their importance to the defense of the state and asserted their political power.

\section{Value Added By Industry}

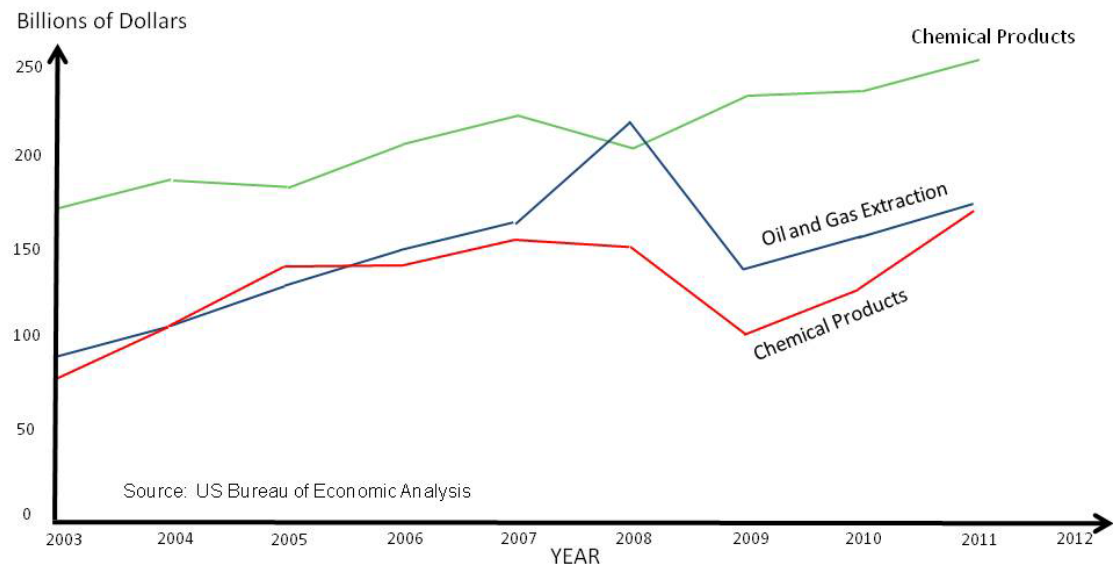

Figure 9: Value added for selected industries.

In our present day, the manufacturing facility is analogous to the great triremes of ancient Greece. Our duty, however, is to insure that the processing plants of today do not crash on the rocky coast of the beckoning sirens who promise higher profits via cheap and unqualified labor.

\section{References}

[1] Case Study, No 2005-02-I-TX, Polyethylene Wax Processing Facility Explosion and Fire, US Chemical Safety and Hazard Investigation Board, June, 2006.

[2] Safety Bulletin, No 2005-04-B, US Chemical Safety and Hazard Investigation Board, October 12, 2006.

[3] Case Study, No 2006-01-I-TX, US Chemical Safety and Hazard Investigation Board, June, 2006.

[4] Case Study, No. 2008-06-I-TX, US Chemical Safety and Hazard Investigation Board, January, 2011.

[5] Dr. Kenneth Harl, "The Peloponnesian War", The Teaching Company, 2007. 